\title{
The place of pain in human experience
}

\author{
Gilbert Lewis Department of Social Anthropology, University of Cambridge
}

In this last of our selection of papers from the London Medical Group Conference on Pain, Gilbert Lewis, through his experiences of living in New Guinea describes to us the various rites, rituals and uses of pain in societies other than our own. He outlines, by example, how what often seems the natural behaviour to us for helping a sufferer in fact, can make matters far worse for other peoples. Although different societies approach the problem of pain from many routes the aim of all is to relieve pain for the sufferers. If the sufferer says he feels relief then that is surely what counts.

Someone's experience of pain cannot be shared or known for certain by another. The experience is private. Yet in ordinary life, and more critically perhaps in medical practice, we often try to appreciate the quality or intensity of someone else's pain. I suppose most people would think that they can guess better what someone else's pain is like if they already know him well. Such intuitions about his pain rest on an imaginative combination of one's own past experience of pain with deductions drawn from observing how the other behaves, and from what he says. But we have no sure grasp. Familiarity with pain felt ourselves and familiarity with the sufferer in the sense of knowing about him, his usual behaviour, his attitudes and ideas, underlie such ability as we have to assess another's pain. It is a matter of cumulative experience and attention. In some respects, a careful observer may learn to assess pain better through special training and experience such as that given to the doctor or nurse.

An anthropologist usually works among people of a culture, language, attitudes and experience different from his own. His assessment of what pain is like for them must involve similar, but often greater, problems of uncertainty, for the language differs, the analogies used to describe pain draw unfamiliar parallels, and their standards of stoicism and behavioural expression during pain need not be the same as his.

\section{Rites and rituals}

Ordeals and self-mutilations have occasionally been witnessed in exotic places as part of legal, ritual or religious institutions. Some of these have seemed so out of the ordinary as to prompt the question whether the people who practised them felt pain in the same way as most of us. For instance, George Catlin in 1832 sketched from life the rites of the Great Spirit. of the Mandan Indians of Missouri as he watched $\overrightarrow{\vec{\omega}}$ the braves hoisted up and swinging from rawhide ${ }^{\circ}$ thongs attached to skewers pierced through the $\overline{\overline{3}}$ flesh of their breast and backs, with other skewers through their arms and legs from which they later $\dot{\omega}$ dragged weights until they were torn free ${ }^{1}$. Pain was $\vec{N}$ chosen to test a man and prove him. Ordeals, usually $N$ of a less horrifying sort, have or had some place in 을 the life of many societies as a test of worth, or were established to mark by pain the high value of some $\mathbb{D}$ new status, position, or role achieved by the man.

There are examples of mutilation or pain self- $\frac{\Phi}{3}$ inflicted in mourning for death in which a bereaved person is expected to give outward signs of his grief (by gashing himself, cutting off a finger) as $\vec{\varphi}$ though to match the inner feeling by a correspons ing outer pain. But, of course, the most widespread use of pain is for punishment. Hurt is inflicted vengefully or to deter. It is used as a sanction. The intrinsic properties of pain which is felt directly by the individual self, and normally so hated and $\stackrel{\square}{\perp}$ feared, make it apt and obvious as a mode of $\overrightarrow{\vec{P}}$ punishment, easy to use and easy to misuse. The $\frac{0}{3}$ idea that torture will make its victim scream the $\bar{D}$ truth is one of the nastiest twists of human reason.

\section{Pain and punishment}

It is not my purpose now to misrepresent the place of pain in other cultures by focusing on the extra- $\delta$ ordinary instances of actively or self-inflicted pain and magnifying them. I would argue that a calcu- $\frac{\rho}{5}$ lating cruel use of pain plays more part in the $D$ repressive or punitive institutions of centralised, impersonal state powers than in those of small $N$ scale societies where people know each other faceto-face. Hurt to those we do not know concerns us $N$ less. Sympathy depends partly on being able to $N$ identify imaginatively with someone else. We strike a 음 tree without concern. We may hurt some creatures 0 callously, yet the more we see them as somewhat $\stackrel{D}{D}$ like ourselves (ant, frog, pet dog) the less easy it $\stackrel{?}{?}$ becomes. What seems to differ among cultures 0 (either comparing various ones in the present, or 0 comparing now with the past) is the readiness to $\stackrel{\AA}{\overparen{D}}$ grant only some partial, or a fully equal humanity $\underset{\mathbb{Q}}{\mathbb{Q}}$ to other races, ethnic groups or classes (such as 
slaves or serfs). A grading in this readiness left the way open for 'inhumanity' to enter in the treatment of those not granted fully equal human status. In effect the morality which governed or governs the infliction of pain differs among cultures not so much in its basic premises as in the field of people whom it is held to apply to - a field that may be restricted to the few who come within one's own group or category of reference, or extended to all men in principle.

The few experiments carefully devised to find if other races or ethnic categories of men differ in their sensitivity to pain have not, so far as I know, provided a sure conclusion. If the threshold at which an Eskimo begins to feel increasing heat as painful differs from that at which a Nigerian or an American feels it, the difference is small and so far remains very doubtful. But, by contrast, it is clear that culture does affect how people respond to pain. Zborowski's well-known work ${ }^{2}$ described how Americans of Italian, Jewish, Irish and 'Old American' origin differed. Among other things, he found that Italians tend to call for immediate relief of pain by any means, such as drugs, and are happy when pain is alleviated. On the other hand, whereas Jewish-Americans also seek relief of pain, they are sceptical or suspicious of the future and tend to keep complaining even after their pain has been diminished. When in pain 'Old Americans' tend to withdraw socially, while both Jewish and Italian Americans prefer the social company of their relatives. His work has been followed by experimental study of differences in pain tolerance. The differences in the levels of tolerance first found may be altered: for example, by telling the JewishAmerican subjects that the purpose of the experiment is to find out whether it is true that JewishAmericans cannot bear such severe pain as 'Old' or 'Yankee' Americans. The level of tolerance was increased after being told this. The levels were found to vary significantly depending on whether the person conducting the experiment was obviously someone like them - of Jewish background - or obviously of Yankee or Italian American extraction. ${ }^{3}$ Zborowski had pointed to various reasons for differences of response - concern with immediate relief of pain or rather desire to know its cause and what implications it might hold for future illness; desire for sympathy and company; values set on silent fortitude, self-reliance and so on.

\section{Expressing pain}

Given the privacy of pain, the sufferer must express it to make it known. Charles Darwin remarked that animals which are normally mute, like the hare, cry out or scream in extreme pain - the cry or groan must alert the others of its kind if they hear it. But Darwin also noted that some animals seem to suffer much pain soundlessly - for instance the horse with a broken leg, silent, trembling, runnelled $\frac{c}{2}$

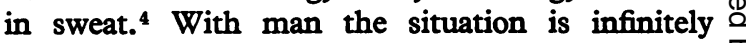
complicated by the advantages of language, culture and social interdependence. Even the startle cry of pain shows some cultural mark - the English $O w$ ! French Aie! New Guinea Udei! Udjiao ! identifies its maker.

Apart from what is instinctive in the moves to ease, escape or cry out the pain, there is a voluntary $\frac{\bar{c}}{\bar{m}}$ element in response which may well not seek to $\widehat{D}$ hide what is felt, but rather seek to alert and reveal how it does hurt. The sufferer needs and wants help. $\%$ The ways to convey this information or to gain $\vec{O}$

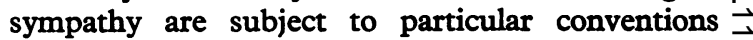
which vary with the standards of fortitude in pain, $\stackrel{\omega}{\sim}$ differing in expectation according to age, sex and status, and the extent to which loud calls for help $\overparen{Ð}$ are approved. The conventions serve to make the $\vec{i}$ behaviour less open to misunderstanding. The conventions vary by culture, as does response to them. $N$

For instance, what I had supposed to be a natural 을 way of showing sympathy only made matters worse for Dauwaras, a man suffering much pain, whom I $\&$ knew when I worked in a village in the north of New $\frac{\mathbb{D}}{O}$ Guinea. His joint pains were understood by himself $\stackrel{\mathbb{D}}{\vec{S}}$ and others as the sign of attack by an afflicting spirit and accordingly he withdrew from normal social life, $\stackrel{\Phi}{?}$ abstained from certain foods and chat. He lay $\vec{\theta}$ apart from others, dirty with ashes and dust on hs skin. He hardly answered if spoken to. The pain persisted and got worse, so he moved to a small das hut in which he stayed alone most of the time. Hît illness was understood to be severe. People came to spend the day sitting with his family and hamlet $\frac{\circ}{D}$ neighbours. They chatted; they ate a meal. The visits $\stackrel{\circ}{\Rightarrow}$ took place on many days during his long illness. Almost no one went to see him or to talk to him, except for those who went explicitly to treat him. I pitied him in his pain and isolation. I passed much of one day chatting to him in a well-meaning effort to cheer him up in what I imagined was a miserable solitude in the dark of the hut. That night his pains 3 . came on redoubled. We had talked about many things - about his illness, possible reasons for it, what the others were doing, about past times, $O$ warfare, his spells of contract labour at the coastal plantations. Next day the senior man in his family, $\frac{D}{0}$ his eldest brother, asked me not to visit him to talk like that; such talk brought on his pain and added $N$ to the risk of the spirit continuing to afflict him, for $N$ it saw that he behaved as a normal man would, and N disregarded the warning threat of death it gave him in the pain.

In this brief illustration, I would point out first, the stereotyped social withdrawal with dirt and griming used to indicate to others, not verbally, but by behaviour, what the patient felt. Additionalmarks of the severity of his pain and his perception that he was seriously ill came later - in the things? he refused to eat, his silence, his abandonment of 
all body covering, even his penis-covering, his selfneglect and dirt. Secondly, the behaviour was responded to by the demonstration of sympathy in terms appropriate for that society - they came to visit, as they said, 'to sit around him', called by the sense of affection as well as duty. His appeal was clear. Later when he got much worse, some slept the night in his hamlet to show concern for him still they did not talk or sit with him, but only towards the end, some came to weep over him. They came into the doorway of the hut and squatted down to weep or wail at the sight of him. Dauwaras, the man, realised how many people had come, and on so many days, to show him sympathy (he was worried at the work it meant for the women of his extended family and the drain on his brothers' food resources) but he was touched by their sympathy: for their tears, he said he would repay them, as custom expected.

\section{Pain and its significance}

The example also calls for comment on the attention given pain in that society and their views on its significance. Our first impulse when we learn someone is in pain, is to ask how bad it is and where it hurts. We learn as doctors to ask more detailed questions about it because the answers may be pertinent to discovering its cause and deciding what to do. As patients or doctors we recognise that pain may indicate the seat of damage, the kind of disorder, and thus help to guide efforts at treatment. The pain is informative as well as hateful. The New Guinea people I lived with did not view pain in quite the same way. If they wished to, they were able to specify the location of pain and, by some turns of speech, identify a few differing qualities and the intensity of pain. But they did not normally bother to do this precisely in present illness which they judged serious - rather than talk about the pain, they would show it by the behaviour I have described. If I asked them, they would often tend to answer casually that they felt pain all over. In their view the localisation and quality of pain was not, in general, a useful guide to the cause or treatment. They had no words, like angina or migraine, that distinguish a special kind of pain because it indicates the cause or characterises a type of illness. Pain was not informative to them in that sense. Also, perhaps there was less reason to speak about it much in the hope of some remedy specific for pain, since all they had to relieve it were nettles for rubbing the skin, or alternatively they made little cuts nicking the skin where it hurt to let 'bad blood' out.

What they wished to understand was the punitive, warning or vengeful nature of pain. Perhaps we might remember here that our English word 'pain' first meant punishment. To the New Guinean people I studied the pain which comes from no visible injury, no burn or scald or cut, is likely to have come not by accident but by design. There is 2 a wish to make sense of the suffering as something $\underset{F}{F}$ caused for a reason, and a reason understandable $\overline{\bar{\delta}}$ because it is like some reason that prompts men to hurt others. If an answer can be worked out from $\overrightarrow{\overline{\vec{S}}}$ examining the circumstances of the patient, from $\overline{0}$ considering his friendships, enmities, disputes, or 당 his actions involving things which invisible spirits $\frac{\bar{\omega}}{\bar{s}}$ are interested in, so it may be possible to remedy $\widehat{\nabla}$ the relationships upset, or appease the spirit supposed to be angered. They search to find who or ${ }^{\infty}$ what is (morally) responsible for the particular $\vec{\circ}$ person's suffering at that time in case they can do $\overrightarrow{\vec{\omega}}$ something to avert it.

With Dauwaras, the diagnosis of the spirit attacking him played a part in the later attention he $\overparen{\Phi}$ gave his pain. The spirit was concerned with the successful growth of certain plants, especially bananas and yams. Of course he avoided these $N$ foods; but he still found that he had pain and it got 의 much worse when people passed near where he lay carrying bananas or yams. So barriers were put at $\Phi$ a distance round him to keep people off lest the $\frac{O}{P}$ influence of the spirit following its foods renew his $\frac{\mathbb{D}}{3}$ suffering. These measures releved him a little. The spirit then began to trouble him in his dreams appearing in its dream-form as a great black pig, $\vec{\theta}$ and he woke to agony following such dreams. TR $\infty$ attention he gave his pain stemmed from the pat itself, but also his suffering reflected the significan he attached to his pain, what it meant to him in terms of the spirit cause, its power and his knowledge of those he had known in the past who had $\stackrel{2}{\circ}$ died by it. In his case, though they tried to heal him by performing the great rites of the spirit, they $\frac{0}{3}$ failed, his pain persisted. Then they and he realised that there must be some additional cause, yet undiscovered and malignant, seeking his ruin.

\section{Why do we suffer pain?}

Dauwaras was a good man in the view of the people in his village. The problem is the ancient one set in $३$ the Book of Job. It was the same for Dauwaras:0 Why does the righteous man suffer pain ? To most people in the past, as well as many in the present, 음 the problem of individual pain has been answered by accounting for it in terms which would give some $O$ understanding of a motive or purpose behind it, by ${ }^{N}$ seeing it as sanction, vengeance, trial or test of N worth, warning. The finding of an intelligible $O$ reason might offer some chance of remedy, escape, for instance, by expiation of some fault. Comparatively few cultures take or have taken the view that $\stackrel{\oplus}{+}$ severe pain just occurs as the result of some derailment of nature which is meaningless in moral terms. But a doctor now, in principle, should not be con- $\overrightarrow{\mathbb{D}}$ cerned with questions of whether someone's pain $\overrightarrow{\mathbb{D}}$ be just or unjustly suffered, merited or not. He is $\frac{\varrho}{\sigma}$ 
concerned with it as a complaint he would like to be able to relieve, ideally with a safe remedy that acts quickly and always works; and he is also concerned with it as a symptom that may help him diagnose correctly what is wrong and how to treat it. But we have learnt from clinical and experimental study that complaints of suffering pain are not simple responses to bodily change and damage but are affected by fear about the pain, and its significance to someone in a particular situation. Many societies knew almost nothing right (according to our present medical understanding) about what was going on inside the body to produce pain. They had to rely on such help as they could provide by explaining why the person suffered, and by offering the hope of remedy through what were sometimes spectacular demonstrations of help and the desire to make the patient better, in ceremonies of treatment which showed the concern we call sympathy and kindness. Without drugs or medical knowledge, many peoples have had to care for those in pain and try to bring them some relief. What they did, by the testimony of the sufferers, did help to make the pain more bearable. With regard to pain, that criterion - that the sufferer says he feels relief - is the one that counts.

\section{References}

${ }^{1}$ Catlin, G (1867). O-kee-pa. London. Trüber \& Co.

${ }^{2}$ Zborowski, $M$ (1952). 'Cultural components in responses to a pain'. Fournal of Social Issues, 8, 16-30.

${ }^{3}$ Wolff, B B and Langley, S (1968). 'Cultural factors and the response to pain: a review'. American Anthropologist, 70, 494-50r.

${ }^{4}$ Darwin, C (1873). The expression of the emotions in man and animals. London. John Murray. 